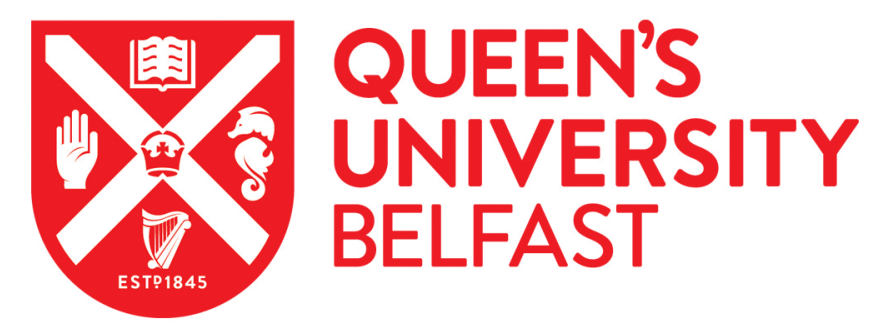

\title{
Concentrations of urinary arsenic species in relation to rice and seafood consumption among children living in Spain
}

Signes-Pastor, A. J., Vioque, J., Navarrete-Muñoz, E. M., Carey, M., García de la Hera, M., Sunyer, J., Casas, M., Riaño-Galán, I., Tardón, A., Llop, S., Amorós, R., Amiano, P., Bilbao, J. R., Karagas, M. R., \& Meharg, A. A. (2017). Concentrations of urinary arsenic species in relation to rice and seafood consumption among children living in Spain. Environmental Research, 159, 69-75. https://doi.org/10.1016/j.envres.2017.07.046

\section{Published in:}

Environmental Research

\section{Document Version:}

Peer reviewed version

Queen's University Belfast - Research Portal:

Link to publication record in Queen's University Belfast Research Portal

\section{Publisher rights}

Copyright 2017 Elsevier.

This manuscript is distributed under a Creative Commons Attribution-NonCommercial-NoDerivs License

(https://creativecommons.org/licenses/by-nc-nd/4.0/), which permits distribution and reproduction for non-commercial purposes, provided the author and source are cited.

\section{General rights}

Copyright for the publications made accessible via the Queen's University Belfast Research Portal is retained by the author(s) and / or other copyright owners and it is a condition of accessing these publications that users recognise and abide by the legal requirements associated with these rights.

Take down policy

The Research Portal is Queen's institutional repository that provides access to Queen's research output. Every effort has been made to ensure that content in the Research Portal does not infringe any person's rights, or applicable UK laws. If you discover content in the Research Portal that you believe breaches copyright or violates any law, please contact openaccess@qub.ac.uk. 


\section{Concentrations of urinary arsenic species in relation to rice and seafood consumption among children living in Spain}

Antonio J. Signes-Pastor $^{a}{ }^{*}, 1$, Jesus Vioque ${ }^{b, c}$, Eva M. Navarrete-Muñoz ${ }^{\text {b,c }}$, Manus Carey ${ }^{a}$, Manoli García de la Hera ${ }^{b, c}$, Jordi Sunyer ${ }^{\mathrm{c}, e, f}$, Maribel Casas ${ }^{\mathrm{c}, e, f}$, Isolina Riaño-Galán ${ }^{\mathrm{c}, \mathrm{g}}$, Adonina Tardón $^{\mathrm{c}, \mathrm{h}}$, Sabrina Llop ${ }^{\mathrm{c}, \mathrm{i}, \mathrm{j}}$, Rubén Amorós ${ }^{\mathrm{j}}$, Pilar Amiano ${ }^{\mathrm{c}, \mathrm{k}, 1}$, José R. Bilbao ${ }^{\mathrm{m}}$, Margaret R. Karagas ${ }^{d}$, Andrew A. Meharg ${ }^{a}$

a Institute for Global Food Security, Queen's University Belfast, David Keir Building, Malone Road, Belfast BT9 5BN, Northern Ireland, UK

${ }_{i s \in p_{i}}^{b}$ University Miguel Hernández, Faculty of Medicine and Institute for Health and Biomedical Research (ISABIAL-FISABIO Foundation), Ctra. Valencia s/n, 03550 Sant Joan d'Alacant, Spain

${ }_{\text {isepic }}^{i c}$ Spanish Consortium for Research on Epidemiology and Public Health (CIBERESP), Spain

istepd Department of Epidemiology, Geisel School of Medicine, Dartmouth College, 1 Medical Center Dr, 7927 Rubin Bldg, Lebanon NH03766, USA

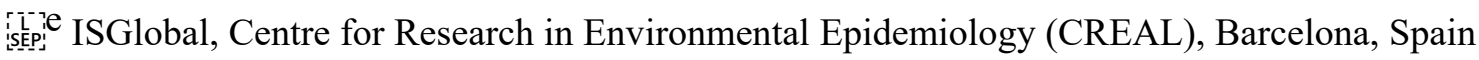
iseped Universitat Pompeu Fabra, Barcelona, Spain

g Pediatric Unit, Hospital Universitario Central de Asturias, Oviedo, Spain

${ }_{\text {istep: }}^{\text {ind }}$ IUOPA-Universidad de Oviedo, Spain

i Epidemiology and Environmental Health Joint Research Unit, Universitat Jaume I-Universitat de València, València, Spain is:pep:

$\mathrm{j}$ Foundation for the Promotion of Health and Biomedical Research in the Valencian Region, FISABIO, Valencia, Spain

${ }^{\mathrm{k}}$ Carlos III Institute of Health, Avenida Monforte de Lemos 5, 28029, Madrid, Spain

${ }^{1}$ Public Health Department of Gipuzkoa, Government of the Basque Country, Avenida Navarra, 4, 20013, San Sebastian, Spain; Biodonostia Research Institute, Paseo Dr Beguiristain s/n, 20014, San Sebastian, Spain

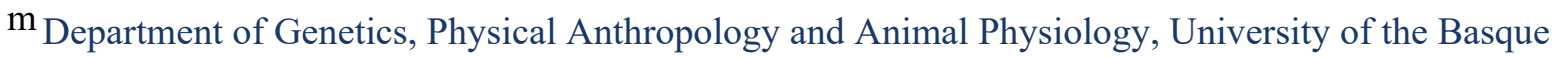
Country (UPV-EHU), BioCruces Health Research Institute, Leioa, Spain.

* Corresponding author.

${ }^{1}$ A.J.S.P is currently working at Dartmouth College. 


\begin{abstract}
Inorganic arsenic (i-As) has been related to wide-ranging health effects in children, leading to lifelong concerns. Proportionally, dietary i-As exposure dominates in regions with low arsenic drinking water. This study aims to investigate the relation between rice and seafood consumption and urinary arsenic species during childhood and to assess the proportion of urinary i-As metabolites. Urinary arsenic species concentration in 4004 -year-old children living in four geographical areas of Spain, in addition to repeated measures from 100 children at 7 years of age are included in this study. Rice and seafood products intake was collected from children's parents using a validated food frequency questionnaire (FFQ). At 4 years of age, children's urine i-As and monomethylarsonic acid (MMA) concentrations increased with rice product consumption ( $p$-value $=0.010$ and 0.018 , respectively), and urinary arsenobetaine $(\mathrm{AsB})$ with seafood consumption $(p=0.002)$. Four-year-old children had a higher consumption of both rice and seafood per body weight and a higher urinary \%MMA $(p$-value $=0.001)$ and lower $\%$ dimethylarsinic acid $(\mathrm{DMA})(p$-value $=0.017)$. This study suggests increased dietary i-As exposure related to rice product consumption among children living in Spain, and the younger ones may be especially vulnerable to the health impacts of this exposure also considering that they might have a lower i-As methylation capacity than older children. In contrast, seafood consumption did not appear to influence the presence of potentially toxic arsenic species in this population of children.
\end{abstract}

Keywords: Food frequency questionnaire; Arsenic speciation; Inorganic arsenic; Rice; Seafood; Urinary biomarker; Young children; Childhood. 


\section{Funding sources}

This work was funded by a Marie Curie Intra-European Fellowship within the $7^{\text {th }}$ European Community Framework Programme (RICENIC project - PIEF-GA-2013-622096) and the INMA project (http://www.proyectoinma.org/), which is supported by grants from UE (FP7ENV-2011 cod 282957 and HEALTH.2010.2.4.5-1), and from Spain: Instituto de Salud Carlos III (Red INMA G03/176, CB06/02/0041, FIS-FEDER 03/1615, 04/1509, 04/1112, 04/1436, 04/1931, 04/2018, 05/1079, 05/1052, 06/0867, 06/1213, 07/0314, 08/1151, 09/00090, 09/02311, 09/02647, 11/0178, 11/01007, 11/02591, 11/02038, 13/1944, 13/2032, 13/02187, 13/02429, 14/0891, 14/1687 and Miguel Servet-FEDER CP15/00025), CIBERESP and the Conselleria de Sanitat, Generalitat Valenciana. Generalitat de Catalunya-CIRIT 1999SGR 00241, Fundació La marató de TV3 (090430). Obra Social Cajastur/Fundación Liberbank and Universidad de Oviedo. Department of Health of the Basque Government (2005111093, 2009111069 and 2013111089), and the Provincial Government of Gipuzkoa (DFG06/004 and DFG08/001). Annual contracts with the municipalities of the study area (Zumarraga, Urretxu, Legazpi, Azkoitia y Azpeitia y Beasain). A.J.S.P. and M.R.K. are funded by U.S. National Institutes of Environmental Health Sciences grant P01ES022832 and RD 83544201 from the U.S. EPA, and participated in the Collaborative on Food with Arsenic and associated Risk and Regulation (C-FARR). The authors declare they have no actual or potential competing financial interests.

Informed consent was obtained from all participants in each phase, and the hospital ethics committees in the participating regions approved the study. 


\section{Introduction.}

There is sufficient evidence in humans for carcinogenicity due to i-As oral exposure (IARC, 2012). Other than cancer, exposure to $i$-As has been associated with a wide range of adverse health outcomes including neurological, cardiovascular, respiratory and metabolic diseases (Medrano et al., 2010; Naujokas et al., 2013; Tsuji et al., 2014). Fetal and early life exposure to i-As is of particular concern due to the specific vulnerability to the adverse health effects of i-As, which may have a marked impact throughout the lifespan even at low to moderate levels of exposure (Farzan et al., 2016; Gilbert-Diamond et al., 2016; Rodríguez-Barranco et al., 2016; Vahter, 2009). The metabolic pathway of i-As involves a series of reduction and oxidative methylations, in which i-As is sequentially transformed to MMA and DMA. The metabolic process is incomplete such that $\mathrm{i}$-As along with MMA and DMA metabolites are excreted in urine (Tseng, 2009). Health risks associated with exposure to organic arsenic compounds such as DMA and MMA are less certain than i-As, and AsB, which is excreted in the urine unchanged and regarded as non-toxic (Cubadda et al., 2016; Feldmann and Krupp, 2011; Molin et al., 2015).

Diet is the main source of i-As exposure when relatively low arsenic drinking water is available, the maximum level of which is regulated at $0.01 \mathrm{mg} / \mathrm{l}$ in the EU (Cubadda et al., 2016; EFSA, 2009; The Council of the European Union, 1998). The $0.01 \mathrm{mg} / 1$ is also the WHO guideline value for arsenic in drinking water and thus the legal limit in many countries around the world (WHO, 2011). Rice and rice-based products contain higher levels of i-As compared to other foodstuff, in addition to DMA and traces of MMA, and therefore they are an important i-As dietary source (Meharg et al., 2008; Signes-Pastor et al., 2016a, 2016b; Williams et al., 2007). This is an increasingly recognized issue for infants and young children whose food consumption per body weight is higher compared to adults, and rice products 
generally predominate their diet due to the putative organoleptic and nutritional quality, and relatively low allergic potential of these products (Burló et al., 2012; Da Sacco et al., 2013; Karagas et al., 2016; Meharg et al., 2008; Signes-Pastor et al., 2016b). New regulations regarding maximum levels of $\mathrm{i}$-As in rice and rice-based products have been recently established in the European Union (EU) with the most restrictive level of $0.1 \mathrm{mg} / \mathrm{kg}$ set for rice-based foods for infants and young children (EC, 2015). The $0.1 \mathrm{mg} / \mathrm{kg}$ i-As threshold is also a draft "action level" in the United States (U.S.) (FDA, 2016). As far as seafood is concerned, AsB dominates in fish, whereas other organic arsenic compounds such as arsenosugars and arsenolipids are also found in seafood products, including i-As in bivalves, crustaceans and algae (Feldmann and Krupp, 2011; Fontcuberta et al., 2011; Krishnakumar et al., 2016; Molin et al., 2015; Navas-Acien et al., 2011; Taylor et al., 2016). Thus, if relatively low arsenic drinking water is available, rice and seafood products are principal total arsenic, including potentially toxic arsenic species, dietary sources (Cubadda et al., 2016; EFSA, 2009). However, limited information is as yet available regarding the contribution of these key food items to urinary arsenic species concentration as exposure biomarker during childhood, especially among those with increased and consistent rice and seafood product consumption, such as those living in Spain, whose consumption of rice and seafood products is enhanced by the Spanish gastronomic culture.

In this study, the relations between the arsenic species and their summation (excluding AsB) concentrations in urine from 4-year-old children participating in a mother-child prospective cohort study, and rice and seafood product intake were determined. Further, the percentage of urinary i-As, MMA, and DMA were assessed in children at 4 and 7 years of age.

\section{Methods.}


2.1. Study population. The study population here belongs to the mother-child pair participants in the INMA - INfancia y Medio Ambiente - Environment and Childhood project, a prospective population-based birth cohort study conducted in various Spanish regions, www.proyectoinma.org (Guxens et al., 2012). Women participants of the INMA project were recruited at the beginning of their pregnancy (2003-2006) at their reference primary health care centers or public hospitals, and were followed-up until delivery $(\mathrm{n}=2,625)$. All women met the inclusion criteria of $\geq 16$ years old, singleton pregnancy, non-assisted conception, delivery scheduled at the reference hospital, and adequate knowledge of the Spanish language to understand and complete the questionnaires accurately. Their children were enrolled at birth and were followed-up during infancy and childhood.

2.2. Samples collection. Spot urine samples were collected from a study population of 400 children of 4 years of age comprised of four groups of 100 children evenly distributed between boys and girls, and randomly chosen from each of the Spanish sub-cohorts of Asturias, Gipuzkoa, Sabadell, and Valencia, situated in the north and east of the country; Bay of Biscay and Mediterranean coast, respectively. Additionally, urine samples of the same children from the Valencia sub-cohort were collected at 7 years of age $(n=100)$.

Informed consent was obtained from all participants in each phase, and the hospital ethics committees in the participating regions approved the study.

2.3. Anthropometric data and questionnaires. Parental sociodemographic and socioeconomic characteristics were collected through a maternal questionnaire in their $1^{\text {st }}$ trimester of pregnancy including living area, parents education, and social class according to maternal and paternal occupation coded using the International Standard Classification of Occupations (ISCO88) (International Labor Office (ILO), 2012). Trained staff measured children's weight and height following standard protocols. Children's body mass index (BMI) was calculated in 
$\mathrm{kg} / \mathrm{m}^{2}$. Four-year-old children's dietary intake was assessed with a validated FFQ asking about consumption of 105 food items in the previous year (Vioque et al., 2016). Parents or children's guardians provided the information regarding children's diet, and it was recorded in the FFQ during personal interviews administered by trained nutritionists. The usual daily total energy intake for each child was calculated by multiplying the frequency of the use of each food item by the nutrient content of the portion size specified in the FFQ. Total energy values were primarily obtained from food composition tables from the U.S. Department of Agriculture (USDA, 2016), and other published sources reporting information on content in Spanish food (Palma et al., 2008). Rice products included 3 food items referring to cooked rice and breakfast cereal consumption. Seafood products gathered several food items $(n=11)$ including i) surimi products such as seafood sticks and crab sticks, ii) white fish such as hake, sole and sea bream fried or battered, iii) white fish boiled or grilled, iv) swordfish, v) big oily fish such as tuna, bonito, and salmon, vi) small oily fish such as anchovy, sardine and mackerel, vii) canned tuna in oil, viii) canned tuna in brine, ix) squid, cuttlefish, and octopus, x) clams, mussels, and cockles, and xi) prawns, crab, and lobster.

\subsection{Sample preparation and chemical analysis. Children's urinary arsenic speciation} included AsB, DMA, MMA, and i-As, and the levels of which were previously reported in Signes-Pastor et al. (2017) with a median of $9.71 \mu \mathrm{g} / 1,3.97 \mu \mathrm{g} / 1,0.44 \mu \mathrm{g} / \mathrm{l}$, and $0.35 \mu \mathrm{g} / \mathrm{l}$ for the 4004 -year-old children, respectively. The urine samples were stored at or below $-20^{\circ} \mathrm{C}$ until analysis. Then, they were centrifuged and analytical grade hydrogen peroxide was added to convert any arsenite to arsenate to facilitate subsequent chromatographic detection by IC-ICP-MS. Replicate samples of the urine lyophilized material ClinChek ${ }^{\circledR}$ - Control level I (Recipe Chemicals + Instruments GmbH in Munich, Germany), and blank samples were included in each analysis batch as quality control. The specific gravity was measured with a clinical refractometer to normalize urine dilution. The recovery percentages of arsenic 
speciation based on several replicate samples of the urine lyophilized material ClinChek ${ }^{\circledR}$ Control level I $(n=33)$ were $115 \pm 2 \%$ for $\mathrm{i}-\mathrm{As}, 97 \pm 2 \%$ for MMA, $94 \pm 2 \%$ for DMA, and $90 \pm 2 \%$ for $\mathrm{AsB}$. The mean and range concentrations of the arsenic species reference values in the urine lyophilized material ClinChek ${ }^{\circledR}$ - Control level I are as follows: $4.55(2.73-6.37)$ $\mu \mathrm{g} / 1$ for i-As, $2.50(1.50$ - 3.50) $\mu \mathrm{g} / 1$ for MMA, $9.8(5.88$ - 13.7) $\mu \mathrm{g} / 1$ for DMA, and 16.8 $(12.6-21.0) \mu \mathrm{g} / 1$ for AsB. The LOD for arsenic speciation, calculated from DMA calibration, was $0.011 \mu \mathrm{g} / 1$ (Signes-Pastor et al., 2017).

2.5. Statistical analysis. Urinary arsenic species concentrations were log-transformed due to their skewed distribution, and their percentages determined based on $\Sigma$ As, calculated as the summation of i-As, MMA, and DMA concentrations, excluding AsB. Rice and seafood products consumption were adjusted for energy intake using the residual method, a standard method widely used in nutritional epidemiology. The residuals were calculated from a linear regression with the natural logarithm of the food intake modeled as the dependent variable and the natural logarithm of total energy intake as the independent variable. The mean food intake of the population was then added back to the calculated residuals (Willett et al., 1985). The Wilcoxon test was applied to compare 4- and 7-year-old children's BMI, and consumption of rice and seafood products, and to compare their urinary arsenic species profile as percentage of i-As, MMA, and DMA. The Spearman's correlation (Rho) was used to investigate the relationship between rice and seafood product consumption, and urinary arsenic species concentration. Rice products consumption was right skewed, and thus for sensitivity reasons, the Spearman's correlation analysis was also calculated excluding values higher than 3 standard deviations from the mean and those with urinary As species concentrations below the LOD. All statistical analyses and plots were performed using the R Statistical Software (R Core Team, 2014). The limit of detection (LOD) was calculated as the mean of the blank concentrations plus three times the standard deviation of the blank 
concentrations multiplied by the dilution factor. The $1 / 2$ LOD value was assigned for statistical analyses of the data and plots when samples were below the LOD.

\section{Results.}

3.1. Study population. Nearly the entire study population here had Spanish nationality $(>95 \%)$ and was living in urban areas ( $>80 \%)$. Further details regarding selected characteristics of the 4- and 7-year-old children study population are reported in Table $\mathbf{1 .}$

3.2. FFQ. Nearly all children at 4 years of age were reported to be consuming rice and seafood products $(\mathrm{n}=383)$. The remaining 17 participants were missing values for both categories. Four-year-old children's median rice intake was $27.2 \mathrm{~g} /$ day and seafood consumption was $39.9 \mathrm{~g}$ /day with a median percent contribution and range of $87.3 \%(52.2 \%$ $-96.2 \%)$ from fish, $4.1 \%(0.9 \%-40.7 \%)$ from cephalopods, $3.4 \%(0.9 \%-22.3 \%)$ from bivalves, and 3.5\% (1.2\% - 27.2\%) from crustaceous. All 4- and 7-year-old children living in Valencia reported rice and seafood product consumption $(n=100)$. Valencian children's rice product consumption (g/day) increased with age $(p<0.001)$, and a similar trend was found for seafood product consumption $(\mathrm{g} / \mathrm{day})(p=0.062)$. However, their rice and seafood product intake decreased with age when adjusted per body weight $(p=0.043$, and $p<0.001$, respectively) (Table 2).

3.3. As exposure. The urinary AsB concentration was higher than the LOD in all urine samples analyzed. However, 10 (2.5\%), 29 (7.2\%), and 17 (4.2\%) urine samples had DMA, MMA, and i-As concentrations below the LOD for the 4-year-old children dataset, respectively. All the urine samples from 7-year-old children living in Valencia had AsB, DMA, and MMA concentrations higher than the LOD, and only one sample had an i-As level below the LOD. The specific gravity average values for urine samples from children at 4 
years $(n=400)$ and 7 years of age $(n=100)$ were 1.015 and $1.018 \mathrm{~g} / \mathrm{ml}$, respectively. At 4 years of age, children's rice product intake positively correlated with urinary i-As $($ Rho $=$ $0.130 ; p=0.010)$, MMA $(\mathrm{Rho}=0.120 ; p=0.018)$ and more weakly with DMA $($ Rho $=$ 0.094; $p=0.065)$ and $\Sigma$ As $($ Rho $=0.088 ; p=0.083)$ as depicted in Figure 1. When values higher than 3 standard deviations from the mean and those with urinary arsenic species concentration below the LOD were not included in the calculations, the positive correlations between rice product consumption and urinary arsenic species were stronger with urinary iAs $(\mathrm{Rho}=0.177 ; p=0.001)$, similar with urinary MMA $(\mathrm{Rho}=0.113 ; p=0.043)$, and weaker with urinary DMA $(\mathrm{Rho}=0.077 ; p=0.156)$ and $\Sigma$ As $(\mathrm{Rho}=0.061 ; p=0.257)$ compared to the correlations reported earlier when including the entire dataset in the calculations (See Supplemental Material, Figure S1). Further, seafood product consumption had a clear positive correlation with urinary $\mathrm{AsB}$ at 4 years of age $(\mathrm{Rho}=0.153$; $p=0.002$ ). On the contrary, none of the other urinary arsenic species analyzed was clearly associated with seafood product intake (Figure 2). Nor was the urinary $\Sigma$ As clearly associated with seafood product intake $(\mathrm{Rho}=0.069 ; p=0.176)$. Likewise, the combination of bivalve and crustaceous consumption, excluding the other seafood items, had a clear correlation with urinary AsB at 4 years of age $(\mathrm{Rho}=0.122 ; p=0.016)$; however, none of the other urinary arsenic species was clearly associated with the bivalve and crustacean consumption $(\mathrm{Rho}=0.020 ; p=0.687$ for $\mathrm{i}-\mathrm{As}, \mathrm{Rho}=0.007 ; p=0.882$ for $\mathrm{MMA}, \mathrm{Rho}=$ $0.088 ; p=0.082$ for DMA, and Rho $=0.088 ; p=0.083$ for $\Sigma$ As $)$.

In the repeated urinary arsenic species measures from children from Valencia, we observed higher urinary \%DMA at 7 years of age (mean, $83 \%$; range, $70-96 \%$ ) than at 4 years (mean, $81 \%$; range, $55-96 \%)(p=0.017)$, and lower $\%$ MMA (mean, $8.7 \%$ and $7.4 \%$; range, $0.1-$ $21 \%$ and $1.6-15 \%$, for children of 4 and 7 years of age, respectively) $(p=0.001)$. Children of 4 years of age had a mean and range urinary $\%$ i-As of $10 \%$ and $1.3-28 \%$ compared to 
that of $9.0 \%$ and $0.2-22 \%$ at 7 years $(p=0.162)$ (Figure 3$)$.

\section{Discussion.}

Diet is the main source of $\mathrm{i}$-As and other potential toxic arsenic species in regions with access to relatively low i-As drinking water. This is especially true for infants and young children whose diet is generally of lower food diversity, and characterized with a higher food consumption per body weight compared to adults, which in turn exacerbates dietary exposure (Cubadda et al., 2016; EFSA, 2009; Karagas et al., 2016). In our study children at 4 years of age had higher rice and seafood product consumption per body weight than at 7 years. A strong influence of the Spanish gastronomic culture was reflected in a high regular consumption of rice and seafood products allowing us to assess the contribution of these products to children's urinary arsenic species concentration.

One of the limitations of our study is the lack of individual data on household water concentrations of i-As. However, in Spain, each autonomous regional public health administration is in charge of monitoring tap water quality and maintaining arsenic levels below the maximum EU standard. Indeed, published records indicate very low arsenic concentrations with a median $<1 \mu \mathrm{g} / \mathrm{l}$, and a high percentage of water samples compliance with the arsenic drinking water regulation ranging from 97\% to 100\% between 1996 and 2011 (Espejo-Herrera et al., 2013; Palau Miguel and Guevara Alemany, 2011; The Council of the European Union, 1998). Likewise, levels far below $10 \mu \mathrm{g} / \mathrm{l}$ have also been reported in bottled water sold in Spain despite bottled natural mineral water, the most consumed type of bottled water in Spain, not being subjected to any physicochemical treatment (Espejo-Herrera et al., 2013; The Council of the European Union, 1998). Also, urinary arsenic species concentration is commonly used as a biomarker of short-term exposure to i-As. However, it can be a reliable source of long-term exposure among individuals with consistent intake 
patterns (Kile et al., 2009; Marchiset-Ferlay et al., 2012; Navas-Acien et al., 2009). Further, in this study, the children's usual diet was measured in personal interviews with parents and children's guardians using a validated FFQ, which although reliable may be subject to misclassification (Vioque et al., 2016).

Only a few studies have assessed the association between childhood rice products consumption and urinary arsenic species concentration, as recently reviewed (Davis et al., 2017). Consumption of rice has been related to an increase of urinary DMA and MMA in children at 6 to 11 years old from the U.S. belonging to the National Health and Nutrition Examination Survey (NHANES) (Davis et al., 2014; deCastro et al., 2014). Further, in children 5 to 8 years old with low i-As exposure from water residing in Uruguay, an increase of consumption of $5 \mathrm{~g}$ of rice per day, assessed via 24-h dietary recall, was associated with a 1.2- and 1.1-fold increment of urinary $\Sigma$ As and \%DMA, respectively (Kordas et al., 2016). In our current study of 4-year-old children, consumption of rice and rice products was higher than in Uruguay where the median consumption was $0 \mathrm{~g}$ /day (Kordas et al., 2016), and we found consumption to be positively correlated with urinary i-As and MMA concentrations. We also found a positive trend between rice product intake and urinary DMA, but not as clearly as that reported in previous studies focused on older children or adults (Cascio et al., 2011; Davis et al., 2017; Kordas et al., 2016; Meharg et al., 2014). This may have resulted from the consumption of rice with a relatively high percentage of i-As, such as that grown in the Iberian Peninsula, including Portugal and Spain, with a median i-As percentage and range of 57\% (14\% - 95\%) (Signes-Pastor et al., 2016a).

The relative proportion of urinary arsenic species is a widely used measure of an individual's i-As methylation capacity, which is determined at least in part by genetic factors such as polymorphisms in the arsenic methyltransferase (AS3MT) gene (Jansen et al., 2016; Skröder 
Löveborn et al., 2016; Tseng, 2009). Children's ability to methylate i-As has been reported to be more efficient than their mothers (Skröder Löveborn et al., 2016). However, a marked increase in urinary \%MMA has been found in children aged 18 months compared to the same at 3 months, suggesting a lower i-As methylation efficiency during early life (Fängström et al., 2009). Despite the relatively small sample size, our study suggests that the urinary arsenic species content pattern of children of 4 and 7 years old showed higher i-As methylation capacity with age, with higher mean urinary \%DMA and lower mean \%MMA and \%i-As in older children. However, it is important to bear in mind that this study did not take into account potential confounding factors such as direct exposure to DMA from rice consumption and DMA from arsenosugars and arsenolipids metabolism that may weaken the measurement of i-As methylation capacity as a relative proportion of the urinary i-As metabolites concentration (Molin et al., 2014; Signes-Pastor et al., 2016a)

Spain is among the highest seafood consumers in Europe (Navarro Serrano et al., 2016; Taylor et al., 2016), and consequently seafood products were in almost all children's diets included in this study. The 4-year-old children's total seafood intake was primarily fish consumption, which contains predominantly AsB (Molin et al., 2015; Taylor et al., 2016), and thus seafood intake was clearly correlated with the urinary excreted unchanged AsB. There was no evidence of correlation between seafood consumption and i-As or other urinary arsenic species that have been related to potential health effects (Choi et al., 2010; Fort et al., 2014; Navarro Serrano et al., 2016; Navas-Acien et al., 2011). Notably there was no evidence of correlation between the combination of bivalves and crustaceans consumption with urinary i-As or its metabolites despite higher i-As content being commonly reported in bivalves and crustaceans compared to fish and cephalopods including those marketed in Spain (Fontcuberta et al., 2011; Krishnakumar et al., 2016; Taylor et al., 2016). The lack of association between consumption of bivalves and crustaceans with urinary i-As and its 
metabolites may be related to the relatively low and potentially irregular 4-year-old children's consumption of these marine products, which only counted for a median percentage of $7.2 \%$ of the total seafood intake. Therefore, seafood consumption generally does not appear to be a major source of arsenic exposure aside from AsB in this population of children.

\section{Conclusions.}

Our findings suggest that in regions with low i-As drinking water and with a traditional diet of rice and seafood such as in Spain, children's rice and seafood products are key sources of total arsenic dietary exposure including potentially toxic arsenic species. Seafood consumption was associated with an increase of urinary AsB, an unmetabolized form of arsenic that is considered non-toxic. Conversely, urinary i-As and MMA concentrations were clearly related to children's rice intake, consumption of which was higher for younger children (4 years old) compared to older children ( 7 years old) when adjusted per body weight. Future studies need to focus on the association between rice product dietary i-As exposure during childhood and lifelong adverse health outcomes, especially for younger children (4 years old) who might have a lower i-As methylation capacity compared to older children ( 7 years old) as suggested in the present study. However, due to the limitations of the study design and the potential confounding effect of dietary DMA this cannot be unequivocally demonstrated here. 


\section{References.}

Burló, F., Ramírez-Gandolfo, A., Signes-Pastor, A.J., Haris, P.I., Carbonell-Barrachina, A.A., 2012. Arsenic Contents in Spanish Infant Rice, Pureed Infant Foods, and Rice. J. Food Sci. 77.

Cascio, C., Raab, A., Jenkins, R.O., Feldmann, J., Meharg, A.A., Haris, P.I., 2011. The impact of a rice based diet on urinary arsenic. J. Environ. Monit. 13, 257-265. doi:10.1039/c0em00482k

Choi, B.S., Choi, S.J., Kim, D.W., Huang, M., Kim, N.Y., Park, K.S., Kim, C.Y., Lee, H.M., Yum, Y.N., Han, E.S., Kang, T.S., Yu, I.J., Park, J.D., 2010. Effects of repeated seafood consumption on urinary excretion of arsenic species by volunteers. Arch. Environ. Contam. Toxicol. 58, 222-229. doi:10.1007/s00244-009-9333-8

Cubadda, F., Jackson, B.P., Cottingham, K.L., Van Horne, Y.O., Kurzius-Spencer, M., Ornelas, Y., Horne, V., Kurzius-Spencer, M., 2016. Human exposure to dietary inorganic arsenic and other arsenic species: State of knowledge, gaps and uncertainties. Sci. Total Environ. 579, 1228-1239. doi:10.1016/j.scitotenv.2016.11.108

Da Sacco, L., Baldassarre, A., Masotti, A., 2013. Diet's role in the toxicity of inorganic arsenic (iAs): A journey from soil to children's mouth. J. Geochemical Explor. 131, 4551. doi:10.1016/j.gexplo.2012.11.014

Davis, M.A., Gilbert-Diamond, D., Karagas, M.R., Li, Z., Moore, J.H., Williams, S.M., Frost, H.R., 2014. A dietary-wide association study (DWAS) of environmental metal exposure in US children and adults. PLoS One 9. doi:10.1371/journal.pone.0104768

Davis, M.A., Signes-Pastor, A.J., Argos, M., Slaughter, F., Pendergrast, C., Punshon, T., Gossai, A., Ahsan, H., Karagas, M.R., 2017. Assessment of Human Dietary Exposure to Arsenic through Rice. Sci. Total Environ. doi:Accepted for publication - February 2017

deCastro, B.R., Caldwell, K.L., Jones, R.L., Blount, B.C., Pan, Y., Ward, C., Mortensen, M.E., 2014. Dietary sources of methylated arsenic species in urine of the United States population, NHANES 2003-2010. PLoS One 9, e108098. doi:10.1371/journal.pone.0108098

EC, 2015. Commission Regulation 2015/1006 of 25 June 2015 amending Regulation (EC) No 1881/2006 as regards maximum levels of inorganic arsenic in foodstuffs. doi:eurlex.europa.eu/legal-content/EN/TXT/?uri=OJ:JOL_2015_161_R_0006

EFSA, 2009. European Food Safety Authority. Scientific opinion on arsenic in food. EFSA panel on contaminants in food chain (CONTAM).

doi:http://www.efsa.europa.eu/sites/default/files/scientific_output/files/main_documents /1351.pdf

Espejo-Herrera, N., Kogevinas, M., Castaño-Vinyals, G., Aragonéss, N., Boldo, E., Ardanaz, E., Azpiroz, L., Ulibarrena, E., Tardón, A., Molina, A.J., López-Rojo, C., JiménezMoleónn, J.J., Capelo, R., Gómez-Acebo, I., Ripoll, M., Villanueva, 2013. Nitrate and trace elements in municipal and bottled water in Spain. Gac. Sanit. 27, 156-160. doi:10.1016/j.gaceta.2012.02.002

Fängström, B., Hamadani, J., Nermell, B., Grandér, M., Palm, B., Vahter, M., 2009. Impaired arsenic metabolism in children during weaning. Toxicol. Appl. Pharmacol. 239, 208-14. doi:10.1016/j.taap.2008.12.019

Farzan, S.F., Li, Z., Korrick, S.A., Spiegelman, D., Enelow, R., Nadeau, K., Baker, E., Karagas, M.R., 2016. Infant Infections and Respiratory Symptoms in Relation to Arsenic Exposure in a U.S. Cohort. Environ. Health Perspect. doi:http://dx.doi.org/10.1289/ehp.1409282

FDA, 2016. FDA proposes limit for inorganic arsenic in infant rice cereal. 
Feldmann, J., Krupp, E.M., 2011. Critical review or scientific opinion paper: Arsenosugars-a class of benign arsenic species or justification for developing partly speciated arsenic fractionation in foodstuffs? Anal. Bioanal. Chem. 399, 1735-1741. doi:10.1007/s00216010-4303-6

Fontcuberta, M., Calderón, J., Villalbí, J.R., Portaña, S., Espelt, A., Duran, J., Nebot, M., 2011. Total and inorganic arsenic in marketed food and associated health risks for the Catalan population ( Spain ). CIBER of Epidemiology and Public Health ( CIBERESP ), Spain. J. Agric. Food Chem. 10013-10022.

Fort, M., Grimalt, J.O., Casas, M., Sunyer, J., 2014. Food sources of arsenic in pregnant Mediterranean women with high urine concentrations of this metalloid. Environ. Sci. Pollut. Res. 1-10. doi:10.1007/s11356-014-2614-4

Gilbert-Diamond, D., Emond, J.A., Baker, E.R., Korrick, S.A., Karagas, M.R., 2016. Relation between in Utero Arsenic Exposure and Birth Outcomes in a Cohort of Mothers and Their Newborns from New Hampshire. Environ. Health Perspect. doi:10.1289/ehp.1510065

Guxens, M., Ballester, F., Espada, M., Fernández, M.F., Grimalt, J.O., Ibarluzea, J., Olea, N., Rebagliato, M., Tardón, A., Torrent, M., Vioque, J., Vrijheid, M., Sunyer, J., 2012. Cohort profile: The INMA-INfancia y Medio Ambiente-(environment and childhood) project. Int. J. Epidemiol. 41, 930-940. doi:10.1093/ije/dyr054

IARC, 2012. Arsenic, Metals, Fibers and Dusts. A review of human carcinogens. IARC monographs on the evaluation of carcinogenic risks to humans. 100C, 527.

International Labor Office (ILO), 2012. International Standard Classification of Occupations. Isco-08 I, 1-420.

Jansen, R.J., Argos, M., Tong, L., Li, J., Rakibuz-Zaman, M., Islam, M.T., Slavkovich, V., Ahmed, A., Navas-Acien, A., Parvez, F., Chen, Y., Gamble, M. V., Graziano, J.H., Pierce, B.L., Ahsan, H., 2016. Determinants and consequences of arsenic metabolism efficiency among 4,794 individuals: Demographics, lifestyle, genetics, and toxicity. Cancer Epidemiol. Biomarkers Prev. 25, 381-390. doi:10.1158/1055-9965.EPI-15-0718

Karagas, M.R., Punshon, T., Sayarath, V., Jackson, B.P., Folt, C.L., Cottingham, K.L., 2016. Association of Rice and Rice-Product Consumption With Arsenic Exposure Early in Life. JAMA Pediatr. 3766, 1-8. doi:10.1001/jamapediatrics.2016.0120

Kile, M.L., Hoffman, E., Hsueh, Y.M., Afroz, S., Quamruzzaman, Q., Rahman, M., Mahiuddin, G., Ryan, L., Christiani, D.C., 2009. Variability in biomarkers of arsenic exposure and metabolism in adults over time. Environ. Health Perspect. 117, 455-460. doi:10.1289/ehp.11251

Kordas, K., Queirolo, E.I., Mañay, N., Peregalli, F., Hsiao, P.Y., Lu, Y., Vahter, M., 2016. Low-level arsenic exposure: Nutritional and dietary predictors in first-grade Uruguayan children. Environ. Res. 147, 16-23. doi:10.1016/j.envres.2016.01.022

Krishnakumar, P.K., Qurban, M.A., Stiboller, M., Nachman, K.E., Joydas, T. V., Manikandan, K.P., Mushir, S.A., Francesconi, K.A., 2016. Arsenic and arsenic species in shellfish and finfish from the western Arabian Gulf and consumer health risk assessment. Sci. Total Environ. 566-567, 1235-1244. doi:10.1016/j.scitotenv.2016.05.180

Marchiset-Ferlay, N., Savanovitch, C., Sauvant-Rochat, M.P., 2012. What is the best biomarker to assess arsenic exposure via drinking water? Environ. Int. 39, 150-171. doi:10.1016/j.envint.2011.07.015

Medrano, M.J., Boix, R., Pastor-Barriuso, R., Palau, M., Damián, J., Ramis, R., del Barrio, J.L., Navas-Acien, A., 2010. Arsenic in public water supplies and cardiovascular mortality in Spain. Environ. Res. 110, 448-454. doi:10.1016/j.envres.2009.10.002

Meharg, A.A., Sun, G., Williams, P.N., Adomako, E.E., Deacon, C., Zhu, Y.G., Feldmann, 
J., Raab, A., 2008. Inorganic arsenic levels in baby rice are of concern. Environ. Pollut. 152, 746-9. doi:10.1016/j.envpol.2008.01.043

Meharg, A.A., Williams, P.N., Deacon, C.M., Norton, G.J., Hossain, M., Louhing, D., Marwa, E., Lawgalwi, Y., Taggart, M., Cascio, C., Haris, P., 2014. Urinary excretion of arsenic following rice consumption. Environ. Pollut. 194, 181-7.

doi:10.1016/j.envpol.2014.07.031

Molin, M., Ulven, S.M., Dahl, L., Goessler, W., Fliegel, D., Holck, M., Sloth, J.J., Oshaug, A., Alexander, J., Meltzer, H.M., Ydersbond, T.A., 2014. Urinary excretion of arsenicals following daily intake of various seafoods during a two weeks intervention. Food Chem. Toxicol. 66, 76-88. doi:10.1016/j.fct.2014.01.030

Molin, M., Ulven, S.M., Meltzer, H.M., Alexander, J., 2015. Arsenic in the human food chain, biotransformation and toxicology - Review focusing on seafood arsenic. J. Trace Elem. Med. Biol. 31, 249-259. doi:10.1016/j.jtemb.2015.01.010

Naujokas, M.F., Anderson, B., Ahsan, H., Vasken Aposhian, H., Graziano, J.H., Thompson, C., Suk, W.A., 2013. The broad scope of health effects from chronic arsenic exposure: Update on a worldwide public health problem. Environ. Health Perspect. 121, 295-302. doi:10.1289/ehp. 1205875

Navarro Serrano, I., Llorente Ballesteros, M.T., Sánchez Fernández Pacheco, S., Izquierdo Álvarez, S., López Colón, J.L., 2016. Total and speciated urinary arsenic levels in the Spanish population. Sci. Total Environ. 571, 164-171. doi:10.1016/j.scitotenv.2016.07.134

Navas-Acien, A., Francesconi, K.A., Silbergeld, E.K., Guallar, E., 2011. Seafood intake and urine concentrations of total arsenic, dimethylarsinate and arsenobetaine in the US population. Environ. Res. 111, 110-118. doi:10.1016/j.envres.2010.10.009

Navas-Acien, A., Umans, J.G., Howard, B. V., Goessler, W., Francesconi, K.A., Crainiceanu, C.M., Silbergeld, E.K., Guallar, E., 2009. Urine arsenic concentrations and species excretion patterns in American Indian communities over a 10-year period: The strong heart study. Environ. Health Perspect. 117, 1428-1433. doi:10.1289/ehp.0800509

Palau Miguel, M., Guevara Alemany, E., 2011. Calidad del agua de consumo humano en españa. informe técnico 437.

doi:http://www.msssi.gob.es/profesionales/saludPublica/docs/agua_consumo_2011_v3_. pdf

Palma, I., Farran, A., Cantós, D., 2008. Tablas de composición de alimentos por medidas caseras de consumo habitual en España = Taules de composició d'aliments per mesures casolanes de consum habitual a Espanya. McGraw-Hill Interamericana.

R Core Team, 2014. R: A Language and Enrionment for Statistical Computing, R Foundation for Statisical Computing. Vienna. doi:www.r-project.org/

Rodríguez-Barranco, M., Gil, F., Hernández, A.F., Alguacil, J., Lorca, A., Mendoza, R., Gómez, I., Molina-Villalba, I., González-Alzaga, B., Aguilar-Garduño, C., Rohlman, D.S., Lacasaña, M., 2016. Postnatal arsenic exposure and attention impairment in school children. Cortex 4. doi:10.1016/j.cortex.2014.12.018

Signes-Pastor, A.J., Carey, M., Carbonell-Barrachina, A.A., Moreno-Jiménez, E., Green, A.J., Meharg, A.A., 2016a. Geographical variation in inorganic arsenic in paddy field samples and commercial rice from the Iberian Peninsula. Food Chem. 202, 356-363. doi:10.1016/j.foodchem.2016.01.117

Signes-Pastor, A.J., Carey, M., Meharg, A.A., 2016b. Inorganic arsenic in rice-based products for infants and young children. Food Chem. 191, 128-134. doi:10.1016/j.foodchem.2014.11.078

Signes-Pastor, A.J., Carey, M., Vioque, J., Navarrete-Muñoz, E.M., Rodríguez-Dehli, C., Tardón, A., Begoña-Zubero, M., Santa-Marina, L., Vrijheid, M., Casas, M., Llop, S., 
Gonzalez-Palacios, S., Meharg, A.A., Navarrete-Muñoz, E.M., 2017. Urinary Arsenic Speciation in Children and Pregnant Women from Spain. Expo. Heal. 9, 105-111. doi:10.1007/s12403-016-0225-7

Skröder Löveborn, H., Kippler, M., Lu, Y., Ahmed, S., Kuehnelt, D., Raqib, R., Vahter, M., 2016. Arsenic metabolism in children differs from that in adults. Toxicol. Sci. 1-11. doi:10.1093/toxsci/kfw060

Taylor, V., Goodale, B., Raab, A., Schwerdtle, T., Reimer, K., Conklin, S., Karagas, M.R., Francesconi, K.A., 2016. Human exposure to organic arsenic species from seafood. Sci. Total Environ. doi:10.1016/j.scitotenv.2016.12.113

The Council of the European Union, 1998. COUNCIL DIRECTIVE 98/83/EC of 3 November 1998 on the quality of water intended for human consumption. Off. J. Eur. Communities L 330, 32-54.

Tseng, C.H., 2009. A review on environmental factors regulating arsenic methylation in humans. Toxicol. Appl. Pharmacol. 235, 338-350. doi:10.1016/j.taap.2008.12.016

Tsuji, J.S., Perez, V., Garry, M.R., Alexander, D.D., 2014. Association of low-level arsenic exposure in drinking water with cardiovascular disease: A systematic review and risk assessment. Toxicology 323, 78-94. doi:10.1016/j.tox.2014.06.008

USDA, 2016. USDA Food Composition Databases [WWW Document]. USDA. doi:10.1016/B978-0-12-384947-2.00308-1

Vahter, M., 2009. Effects of Arsenic on Maternal and Fetal Health. Annu. Rev. Nutr. 29, 381-399. doi:10.1146/annurev-nutr-080508-141102

Vioque, J., Gimenez-Monzo, D., Navarrete-Muñoz, E.M., Garcia-de-la-Hera, M., GonzalezPalacios, S., Rebagliato, M., Ballester, F., Murcia, M., Iñiguez, C., Granado, F., 2016. Reproducibility and Validity of a Food Frequency Questionnaire Designed to Assess Diet in Children Aged 4-5 Years. PLoS One 11, e0167338. doi:10.1371/journal.pone.0167338

WHO, 2011. WHO guidelines for drinking-water quality. WHO Chron. 38, 104-108. doi:10.1016/S1462-0758(00)00006-6

Willett, W.C., Sampson, L., Stampfer, M.J., Rosner, B., Bain, C., Witschi, J., Hennekens, C.H., Speizer, F.E., 1985. Reproducibility and validity of a semiquantitative food frequency questionnaire. Am. J. Epidemiol. 122, 51-65. doi:10.1093/acprof

Williams, P.N., Villada, A., Deacon, C., Raab, A., Figuerola, J., Green, A.J., Feldmann, J., Meharg, A.A., 2007. Greatly enhanced arsenic shoot assimilation in rice leads to elevated grain levels compared to wheat and barley. Environ. Sci. Technol. 41, 68546859. doi: $10.1021 / \mathrm{es} 070627 \mathrm{i}$ 
Table 1: Selected characteristics of the 4- and 7-year-old children study population.

\begin{tabular}{|c|c|c|}
\hline \multirow[t]{2}{*}{ Characteristics } & $\begin{array}{l}\text { 4-year-old children from } \\
\text { Spain }^{\mathrm{a}}\end{array}$ & $\begin{array}{l}\text { Followed up children from } \\
\text { Valencia at } 4 \text { and } 7 \text { years of age }\end{array}$ \\
\hline & $\mathrm{N}=400, \mathrm{No} .(\%)$ & $\mathrm{N}=100$ \\
\hline \multicolumn{3}{|l|}{ Gender } \\
\hline Female & $200(50 \%)$ & 51 \\
\hline Male & $200(50 \%)$ & 49 \\
\hline \multicolumn{3}{|l|}{ Nationality } \\
\hline Spanish & $377(96 \%)$ & 95 \\
\hline Others & $15(4 \%)$ & 5 \\
\hline $\mathrm{NA}^{\mathrm{b}}$ & 8 & \\
\hline \multicolumn{3}{|l|}{ Living area } \\
\hline Urban & $319(81 \%)$ & 81 \\
\hline Semiurban & $62(16 \%)$ & 17 \\
\hline Rural & $11(3 \%)$ & 2 \\
\hline NA & 8 & \\
\hline \multicolumn{3}{|l|}{ Level of education } \\
\hline \multicolumn{3}{|l|}{ Mother } \\
\hline Primary & $76(19 \%)$ & 23 \\
\hline Secundary & $159(41 \%)$ & 48 \\
\hline University & $156(40 \%)$ & 29 \\
\hline NA & 9 & \\
\hline \multicolumn{3}{|l|}{ Father } \\
\hline Primary & $128(33 \%)$ & 43 \\
\hline Secundary & $173(44 \%)$ & 38 \\
\hline University & $89(23 \%)$ & 19 \\
\hline NA & 10 & \\
\hline \multicolumn{3}{|l|}{ Social class } \\
\hline \multicolumn{3}{|l|}{ Mother } \\
\hline Upper - I+II & $93(24 \%)$ & 18 \\
\hline Middle - III & $112(28 \%)$ & 28 \\
\hline Lower - IV+V & $188(48 \%)$ & 54 \\
\hline NA & 7 & \\
\hline \multicolumn{3}{|l|}{ Father } \\
\hline Upper - I+II & $89(23 \%)$ & 16 \\
\hline Middle - III & $69(18 \%)$ & 23 \\
\hline Lower - IV+V & $226(59 \%)$ & 61 \\
\hline $\mathrm{NA}$ & 16 & \\
\hline
\end{tabular}

anclude 4-year-old children from Asturias, Gipuzkoa, Sabadell, and Valencia.

${ }^{\mathrm{b}} \mathrm{NA}=$ Missing values 
Table 2: Children's rice and seafood product consumption, body weight, and BMI according to their age.

\begin{tabular}{|c|c|c|c|c|c|}
\hline \multirow[b]{2}{*}{ Study population } & \multirow{2}{*}{$\begin{array}{l}\text { Children from Spain }{ }^{\mathrm{a}} \\
\begin{array}{c}\text { 4-year-old } \\
\mathrm{n}=400\end{array}\end{array}$} & \multirow{2}{*}{$\begin{array}{c}i \\
i \\
i \\
i \\
i\end{array}$} & \multicolumn{3}{|c|}{ Children from Valencia } \\
\hline & & & $\begin{array}{c}\text { 4-year-old } \\
n=100\end{array}$ & $\begin{array}{c}\text { 7-year-old } \\
n=100\end{array}$ & $\begin{array}{l}p \text {-value between } \\
\text { 4- and 7-year-old. }\end{array}$ \\
\hline Body weight (kg) & $17.8(16.4-19.8)^{\mathrm{b}}$ & 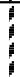 & $17.7(16.5-18.6) \#^{\mathrm{c}}$ & $27.0(23.4-31.0)^{*}$ & $<0.001$ \\
\hline BMI $\left(\mathrm{kg} / \mathrm{m}^{2}\right)$ & $16.0(15.2-17.2)$ & 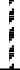 & $15.9(15.2-16.8) \#$ & $16.5(15.5-18.8)^{*}$ & $<0.001$ \\
\hline Rice products (g/day) & $27.2(18.28-39.6)$ & 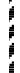 & $28.2(22.5-39.2) \#$ & $35.6(28.3-55.0)^{*}$ & $<0.001$ \\
\hline Seafood products (g/day) & $39.9(31.4-49.5)$ & $i$ & $37.3(26.7-47.1)^{*}$ & $42.4(30.8-52.1)^{*}$ & 0.062 \\
\hline Rice products (g/day) / Body weight (kg) & $1.48(0.86-2.16)$ & 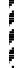 & $1.60(1.21-2.30)^{*}$ & $1.28(0.99-2.00) \#$ & 0.043 \\
\hline Seafood products (g/day) / Body weight $(\mathrm{kg})$ & $2.17(1.68-2.77)$ & i & $2.10(1.51-2.75)^{*}$ & $1.52(1.12-1.95) \#$ & $<0.001$ \\
\hline
\end{tabular}

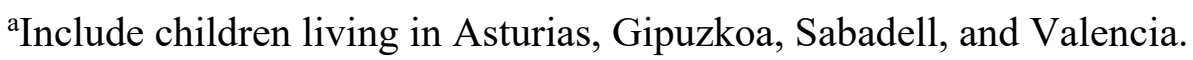

${ }^{b}$ Values reported as median $\left(1^{\text {st }}\right.$ percentile $-3^{\text {rd }}$ percentile $\left.)\right)$.

${ }^{c}$ Values with the same symbol were not significantly different at $p$-value $<0.05$ for the variable studied due to children's age using the Wilcoxon test. 
Figure 1: Spearman correlation between rice products consumption (g/day) and arsenic species in urine from 4-year-old children living in Spain.
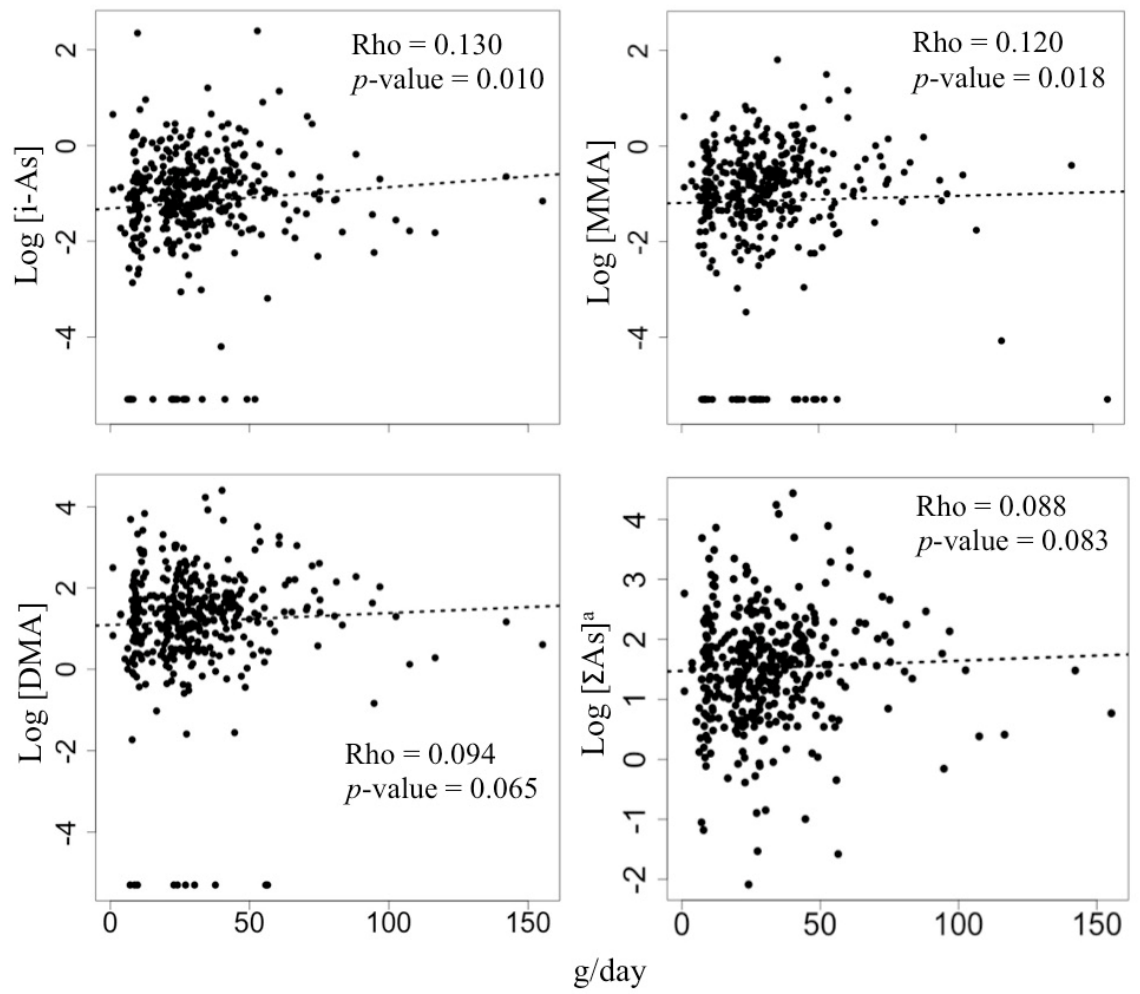

$\mathrm{a}[\Sigma \mathrm{As}]=[\mathrm{i}-\mathrm{As}+\mathrm{MMA}+\mathrm{DMA}]$ 
Figure 2: Spearman correlation between seafood products consumption (g/day) and arsenic species in urine from 4-year-old children living in Spain.
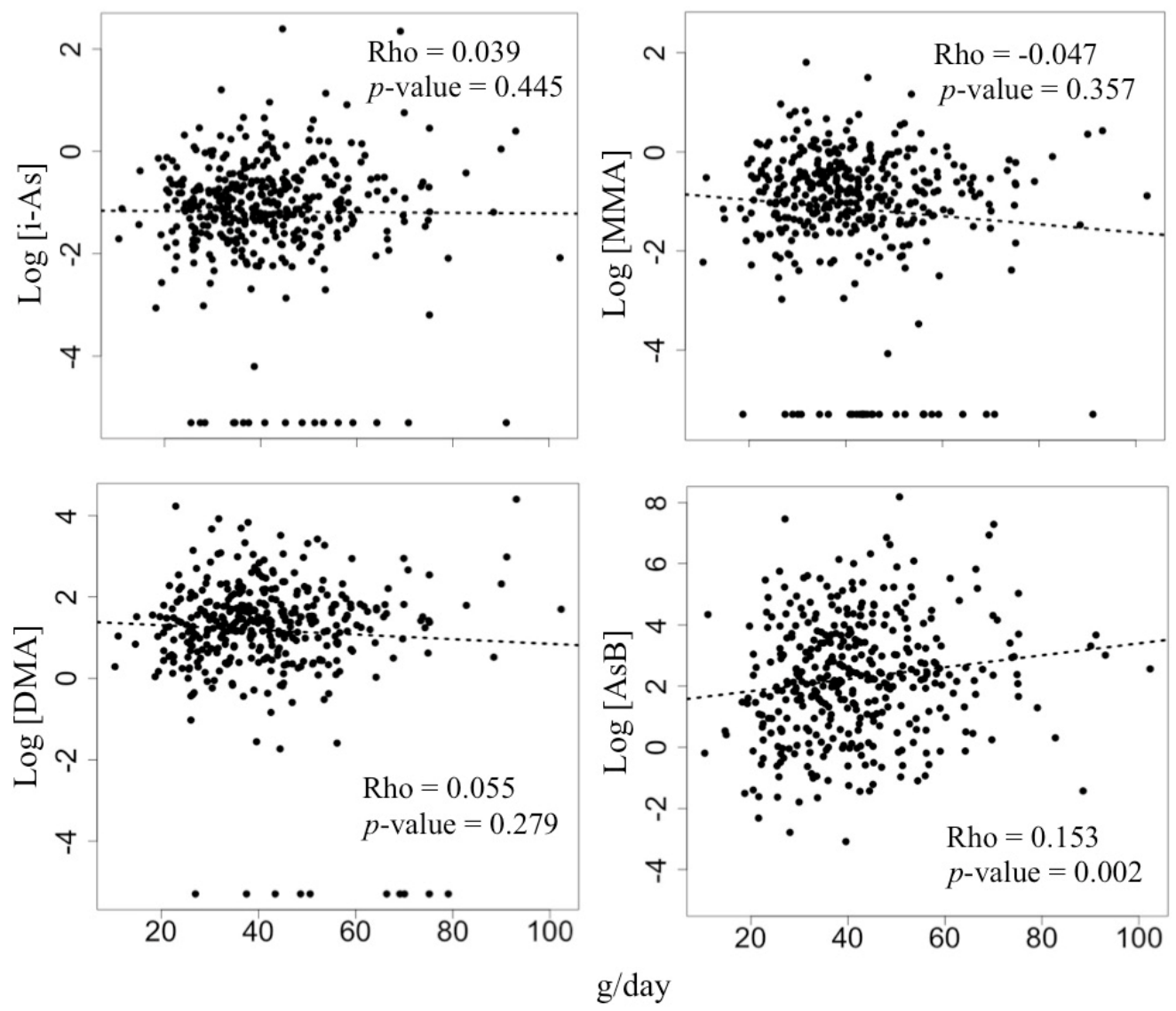
Figure 3: Valencian 4- and 7-year-old children's i-As methylation capacity assessment based on urinary percentage of arsenic species excluding AsB.
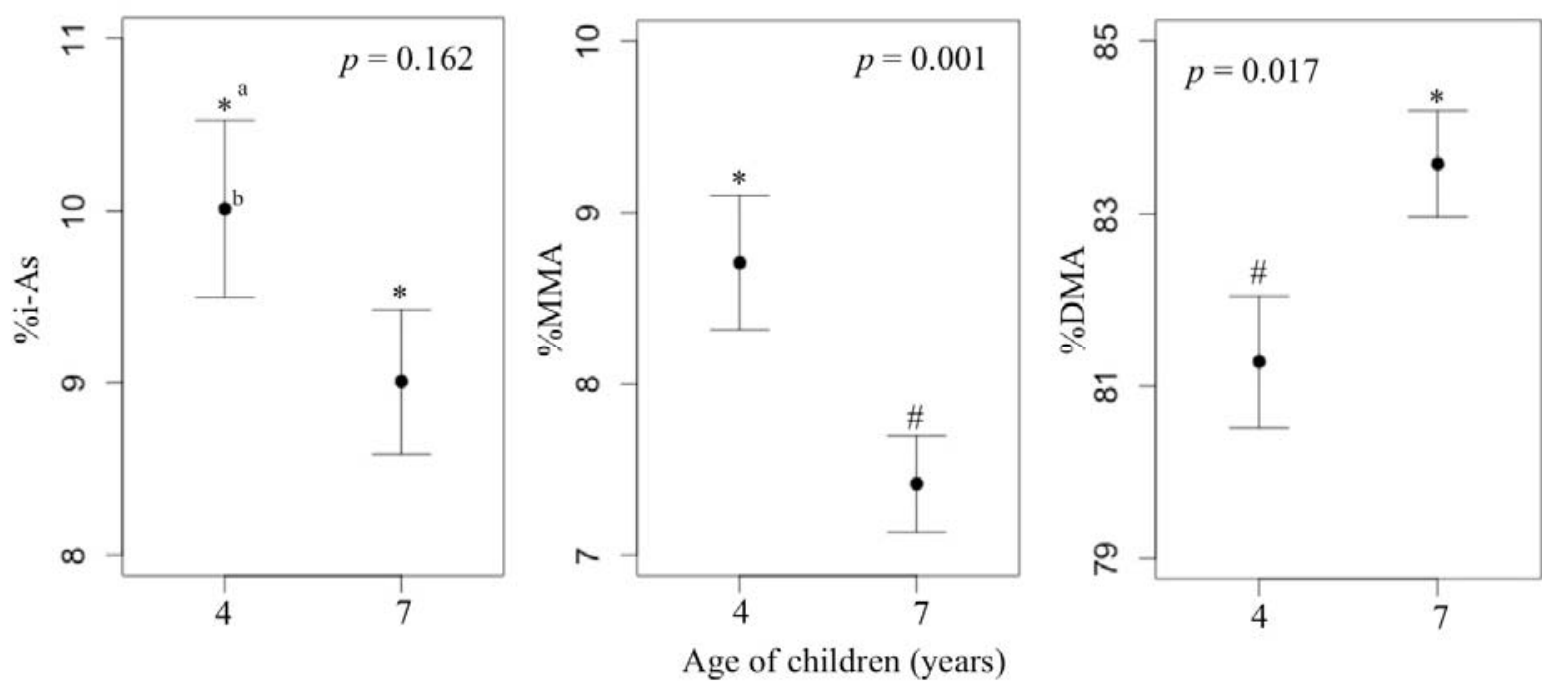

${ }^{a}$ Values with the same symbol were not significantly different at $p$-value $<0.05$ for the variable studied

${ }^{\mathrm{b}} \mathrm{Mean} \pm \mathrm{SE}$ 


\section{Supplemental Material}

Figure S1: Spearman correlation between rice products consumption (g/day) and arsenic species in urine from 4-year-old children living in Spain excluding values outside 3 standard deviations from the mean and those with urinary As species concentration below the LOD.
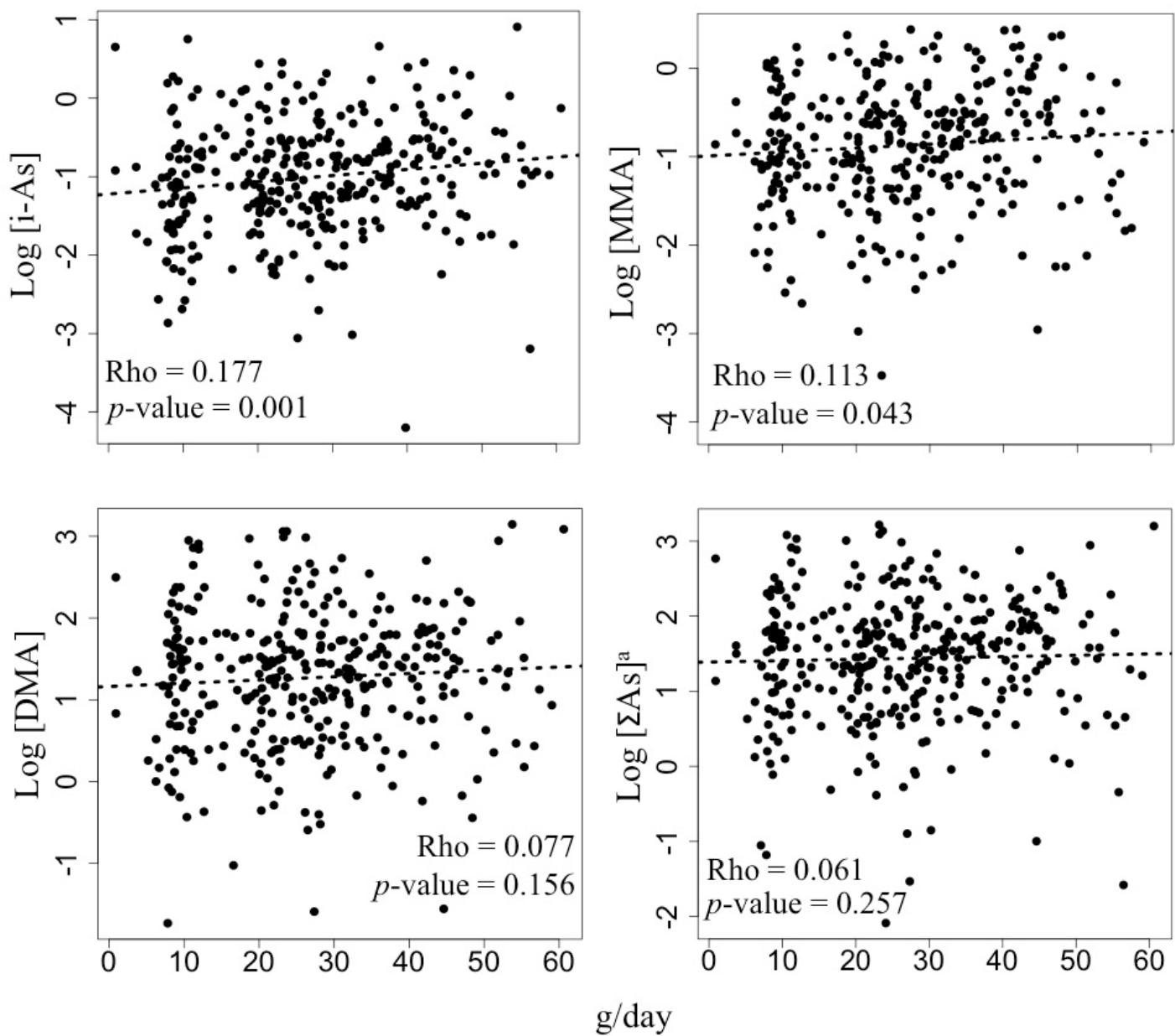

$\mathrm{a}[\Sigma \mathrm{As}]=[\mathrm{i}-\mathrm{As}+\mathrm{MMA}+\mathrm{DMA}]$ 